\title{
TRADUCCIÓN
}

\section{"Nichigetsu-sama" [Soliluna], un cuento de Ango Sakaguchi}

\author{
"Nichigetsu-sama", \\ a story by Ango Sakaguchi
}

\author{
MATÍAS CHIAPPE IPPOLITO \\ Waseda University, Japón
}

Resumen: "Nichigetsu-sama", del escritor japonés Ango Sakaguchi (1906-1955), fue publicado en 1949 y cuenta la historia de Kimigorō Öji, un joven traficante amigo del narrador, un escritor recién dado de alta de un psiquiátrico. En el relato, ambos se encuentran en un bar de uno de los callejones más oscuros de Tokio para compartir una velada de encuentros bizarros e historias perturbadoras.

Palabras clave: Ango Sakaguchi; Burai-ha; decadencia; travestismo; literatura japonesa de posguerra.

Recepción: 23 de agosto de 2019. / Aceptación: 23 de septiembre de 2019. 
Abstract: "Nichigetsu-sama", by Japanese writer Sakaguchi Ango (1906-1955), was published in 1949 and tells the story of Ōji Kimigorō, a young black marketeer who is a friend of the narrator, a writer recently discharged from a mental institution. In the story, they both meet in a bar on one of Tokyo's darkest alleys to share a night of bizarre encounters and disturbing tales.

Keywords: Sakaguchi Ango; Burai-ha; decadence; cross-dressing; Postwar Japanese literature.

\section{Introducción}

Ango Sakaguchi nació en 1906 en la prefectura de Niigata y fue nombrado Heigo Sakaguchi. Su padre, político y presidente del diario Niigata Shinbun, no le prestaba atención sino para obligarlo a preparar la tinta para firmar documentos; su madre, con problemas psiquiátricos y encargada de criar a otros 13 hijos e hijastros, solía golpearlo y encerrarlo en su habitación (Sakaguchi, 1998, pp. 251-253). Ango cuenta que también fue víctima de sus compañeros de escuela, quienes se burlaban de sus anteojos y de su ensimismada personalidad. Se refugió de esta atormentada infancia en el judo, los juegos de cartas y la literatura de aventuras sobre samuráis y la basada en los kōdan, transcripciones de relatos orales antiguos. Fue por estos años que, en la búsqueda por transformarse a sí mismo, cambió su nombre de nacimiento por el de Ango, un seudónimo que usaría por el resto de su vida. En 1922, lo echaron de la escuela. Según el crítico Albert Ryue Ikoma (1979, p. 18), Ango grabó en su pupitre la frase: "Algún día la historia me recordará como un gran fracaso".

Luego de la muerte de su padre en 1923, Ango se convirtió en profesor de la escuela primaria Ebara en Shimokitazawa a fin de apoyar económicamente y desde la distancia a su familia. La desobediencia de sus alumnos lo fascinó, y llegó a escribir que deseaba "descubrir la belleza escondida en esos espíritus rebeldes” (Sakaguchi, 1998, p. 311). Pronto renunció también 
a esa vida. Movido por su interés en el budismo, empezó a estudiar filosofía en la Universidad de Tōyō, francés en el Athénée Français y latín por su cuenta. Estos saberes, aseguró luego, lo ayudaron a borrar sus pensamientos depresivos y a superar la frustración de haber escrito cuentos y novelas con poca repercusión. En 1933, Ango conoció a quien sería su amante, Tsuseko Yada. En 1942 escribió un artículo donde criticaba fuertemente a la sociedad japonesa y que lo volvió famoso: "Nihon bunka shikan" [Mirada personal sobre la cultura japonesa]. En 1946, habiendo sido testigo de los bombardeos a Tokio y tras la derrota del Gran Imperio de Japón, publicó "Darakuron" [Sobre la decadencia], quizá su ensayo más controversial. Por la misma época redactó sus cuentos más reconocidos: "Hakuchi" [Idiotez], de 1946, y "Sakura no mori no mankai no shita" [Bajo los cerezos florecidos en el bosque], de 1947, entre otros. Este corpus definió las características de su estilo, uno cargado de misterio, perversión y sensualidad.

Junto a Osamu Dazai, Sakunosuke Oda y otros, Ango Sakaguchi fue catalogado por la crítica como parte de la Buraiha, la Escuela de Villanos, Decadentes o Degenerados, a veces llamada también Escuela del Cuerpo. Esta caracterización realizada por los críticos más conservadores de la época intentaba enmarcar a autores con tendencias "amorales", sobre todo en lo que respecta al libertinaje sexual y al consumo de narcóticos. En términos menos moralistas, sin embargo, otros críticos afirmaron que la particularidad de estos escritores era su enfrentamiento a la lógica racionalista y su inclinación hacia el nihilismo (Dorsey y Slaymaker, 2010, p. 7). En este sentido, quizá sea posible entenderlos como reaccionarios, disidentes o enemigos del statu quo. En el caso específico de Ango, la crítica al ámbito local no se manifestó a través de un acercamiento a lo internacional y global. Como señaló Donald Keene (1984, p. 1067), más allá de unas traducciones juveniles de Chéjov y de algunos ensayos sobre Mérimée, Stendhal y Dostoievski, Ango escribió poco sobre escritores extranjeros. Enemigo de un pasado tradicional japonés y desconectado de 
la internacionalización que trajo consigo la derrota, Ango vivió la posguerra como los personajes de muchos de sus cuentos: perdido y deambulando constantemente por pasadizos y callejones.

Después del suicidio de su amigo el escritor Osamu Dazai en 1948, Ango entró en una fuerte depresión. Al año siguiente fue internado en el hospital de Tokio debido a su estado mental y a su adicción a los narcóticos. Éstos fueron, sin embargo, años de intensa producción literaria. Entre sus relatos de esta época se encuentra el que se presenta a continuación, traducido por primera vez al español. "Nichigetsu-sama" [Soliluna] es un cuento de 1949 en el cual se narra la historia de Kimigorō Ōji, un joven traficante que consideran excéntrico hasta los personajes más marginales de la sociedad japonesa de posguerra. En el relato se conjugan algunos de los tópicos más comunes de la literatura de Ango: la locura, las drogas, la prostitución, la pregunta sobre la relación entre una cosa y su opuesto.

Ango pasó los últimos años de su vida entre internaciones psiquiátricas y afecciones físicas, agobiado también por un declive en el interés en sus textos. Falleció en 1955 de un aneurisma cerebral.

\section{Referencias}

Dorsey, J. y Slaymaker, D. (2010). Literary mischief: Sakaguchi Ango, culture, and the war. Lanham: Lexington Books.

Ikoma, A. R. (1979). Sakaguchi Ango: His life and work (Tesis de doctorado). Universidad de Hawaii.

KeEnE, D. (1984). Dawn to the West Japanese literature of the modern era. 1. Fiction. Nueva York, NY: Columbia University Press.

SAKaGUCHI, A. (1998). Sakaguchi Ango zenshū [Las obras completas de Sakaguchi Ango] (Vol. 4). Tokio: Chikuma Shobō.

Matías Chiappe Ippolito es licenciado y profesor en letras por la Universidad de Buenos Aires y realizó una maestría en estu- 
dios de Asia y África con especialidad en Japón en El Colegio de México. Vive en Tokio, donde realiza un doctorado en la Universidad de Waseda sobre la relación entre la literatura latinoamericana y la literatura japonesa. Trabaja como investigador para dicha universidad y como profesor de la materia literatura japonesa en traducción para la Universidad Kyoritsu. Tradujo a Kohtaro Orie (Últimas palabras de un eco-terrorista, 2017), a Oriza Hirata (Sayonara, 2018) y a Sion Sono (El club del suicidio, en prensa). Publicó la novela El trueque (2011) y escribe para revistas de cultura como Andén Digital, Cuaderno Waldhuter, y Tokyo Poetry Journal.

https://orcid.org/0000-0001-8421-4513 matchiappe@fuji.waseda.jp 


\section{Soliluna}

Cuando estuve internado en el psiquiátrico empezó a correrse un rumor: que yo era adicto a las drogas. Un día vinieron tres oficiales del Departamento de Narcóticos. Como el Hospital de la Universidad de Tokio no permite interrogar a sus pacientes (podrían enojarse por ser considerados 'adictos a las drogas' y hasta temerían perder la continuidad de sus tratamientos), los tres policías interrogaron en cambio y durante dos horas enteras a la enfermera y al doctor Chitani, quien me tenía a su cargo. Les hicieron pasar un momento de mierda.

Por aquel entonces, yo podía ir al estadio de beisbol Kōraku-en gracias al permiso del doctor Uchimura (el lanzador del equipo de beisbol de los médicos del hospital) y de Chitani (el cácher). Un día en que no había partido, pasé por la casa del escritor Yoshio Toyoshima, muy cerca de allí, en Sendagi.

-Ah... el drogadicto - me dijo al hacerme pasar.

-No soy adicto a ninguna droga, sólo consumo pastillas para dormir.

-Es lo mismo.

No lo contradije.

Después nos pusimos a tomar unos tragos. Eventualmente empezamos a hablar de su hija, que había fallecido el año anterior de peritonitis. Toyoshima dijo que ella sufría dolores insoportables y que por eso se inyectaba Narcopon. Y que al hacerlo sus dolores desaparecían.

-El Narcopon sí es una droga, es un derivado de la morfina - dije-. De hecho, las dos primeras cosas a las que se hizo adicto Osamu Dazai fueron al Narcopon y al Pantopon. En mi hospital no hay camas para cuidados intensivos, así que cuando aparece un paciente muy enfermo se le pone a dormir con Narcopon y se le envía al Hospital Psiquiátrico Matsuzawa. Pero lo que yo tomo son pastillas para dormir comunes y corrientes, ésas que uno compra en cualquier mercado, nada del otro mundo. 
- ¿O sea que las pastillas para dormir y las drogas son cosas diferentes? - preguntó Toyoshima incrédulo.

Incluso los representantes de la élite intelectual japonesa como Toyoshima preguntan de vez en cuando este tipo de idioteces. No es extraño, entonces, que él haya terminado creyéndose el rumor sobre mi adicción a las drogas.

Llegamos entonces a lo que sucedió una semana previa a que me dieran el alta. Un día de esa semana Kimigorō Ōji, un joven traficante, vino a visitarme al hospital. Le digo 'traficante' aunque él detestaría este término. Nos habíamos conocido en un salón de go durante la guerra. Por aquellos años, él operaba los tornos de una fábrica, aunque pronto descubrí que frecuentaba también salones para apostar a los dados. No era un jugador profesional ni vivía de eso; iba de vez en cuando y sólo cuando necesitaba dinero. Pero siempre lo saqueaban. Entonces se tomaba el día libre en la fábrica e iba a un salón de go u otro juego para cambiar de aires. Era una buena persona, pero no habría podido ganarle a nadie ni siquiera si le hubiesen dejado tomar los nueve puntos estratégicos en un tablero de go. Jugaba, debo decirlo, con mucha garra. Y así, lo caracterizaba siempre una mezcla de entusiasmo y decepción.

No nos habríamos hecho tan amigos de haber limitado nuestra relación al salón de go. Cada noche terminábamos también en la misma fila del mismo barsucho y siempre me resultaba conveniente que él estuviera allí para guardarme un lugar. La fila era de unas treinta personas, todos jugadores profesionales o maleantes de diferentes rubros. Kimigorō ni siquiera dudaba en meterse entre ellos y, cuando me veía, me hacía pasar antes que él. Desde ya, comparados con esa gente, nosotros dos no intimidábamos a nadie. Yo me sentía en todo momento fuera de lugar, avergonzado. Mi amigo, por su parte, daba pena de sólo mirarlo.

Después ocurrió el gran bombardeo de Tokio del 10 de marzo. Más de veinte mil o treinta mil casas fueron destruidas y hubo que evacuar la zona fabril donde yo vivía. El gobierno entró en pánico. Informó que la situación se normalizaría en 
alrededor de una semana, pero el caos que se adueñó de todo fue peor que el ataque. Adonde uno fuera, podía ver los intentos por abrir caminos de evacuación: los tanques aplastaban cuanta casa encontraban en su camino, y los estudiantes reclutados por el ejército arrancaban los techos y derribaban las columnas. Un humo apelmazado lo envolvió todo; la gente deambulaba de un lugar a otro, maleta en mano y en total desconcierto. Evidentemente, no se trataba de un incendio común y corriente. Las bombas arrojadas por doquier hicieron surgir las llamas por todos los rincones. Finalmente, las rutas de escape no sirvieron de nada y, al anochecer, el lugar se transformó en una impecable llanura calcinada. Los únicos que se beneficiaron fueron el presidente de la organización de vecinos y sus socios; luego del ataque empezaron la reconstrucción aprovechando las maderas que habían sobrevivido al incendio.

Kimigorō Ōji fue uno de los tantos afectados por la evacuación. Era un joven que iba a salones de apuestas y que lograba siempre colarse entre los primeros de las filas de los barsuchos, sí, pero en el fondo era bastante torpe. Había empacado todas sus cosas y quiso enviarlas al interior, pero el envío se retrasó y tuvo que quedarse en mi casa una semana. Cuando terminó la guerra, regresó a Tokio y vino a visitarme con la intención de quedarse otra vez conmigo. Sin embargo, por ese entonces nuestro barrio estaba desbordado de damnificados y parecía un campamento de refugiados; no pude ofrecerle un espacio y sólo lo hospedé tres, cuatro días. Encontró una habitación y se mudó. Después empecé a verlo revendiendo productos en uno de esos recovecos callejeros que la gente llama 'mercado negro'. Y fue por eso que empecé a llamarlo 'traficante'. Me lo crucé allí durante casi seis meses, hasta que eventualmente dejé de verlo. No lo vi durante los tres años siguientes, al cabo de los cuales me internaron.

Me sorprendió muchísimo cuando vino a visitarme al psiquiátrico. En aquel momento yo estaba solo; no estaba ni mi esposa ni la mujer que me cuida por las noches. Cuando lo vi, me resultó increíble que alguien hubiese podido infiltrarse 
en un hospital tan custodiado, que luego hubiera esquivado la vigilancia y que finalmente hubiese abierto la puerta cerrada de mi habitación. Ni siquiera un periodista o un camarógrafo profesional (esos seres que tienen la misma habilidad que antes tenían los ninjas) habría podido escapar a la mirada de enfermeras y médicos, quienes lo habrían sacado a las patadas.

-Me sorprende que hayas podido entrar.

-Nunca pude agradecerle su ayuda, sensei. Así que le traje este pequeño regalo - dijo con una sonrisa mientras sacaba algo de su saco-. Supuse que estaría pasando un momento difícil y yo... bueno, ahora que tengo mejores contactos, le conseguí esto.

$-¿$ Qué es?

Su sonrisa se transformó en una risa. Mientras se rascaba la cabeza, me mostró una jeringa.

-¿Qué es? -volví a preguntar-. ¿Metanfetamina?

-No. Es una de las tantas drogas que usted usaba, sensei.

Lo miré fijo, sorprendido por la velocidad en que un rumor falso puede transformarse en realidad.

-Entonces... ¿morfina?

-Exactamente, je, je, je, yes.

Mantuvo la sonrisa en su rostro y la mano rascando su cabeza. Sus ojos se llenaron de un raro y profundo afecto.

-Yo nunca la usé, sensei, pero la conozco bien. Si uno es adicto, lo internan enseguida. Pero uno siempre quiere escapar del hospital para volver a usarla, ¿no es cierto? Me preocupé tanto cuando escuché que un hombre como usted estaba encerrado aquí, sin poder contactar a un amigo, sin poder conseguir más... je, je, je. Pero incluso en este lugar al que llaman psiquiátrico, repleto de barrotes, candados y puertas, los pacientes pueden conseguir lo que quieran gracias a mí. Me llaman, nunca pongo excusas; para mí es facilísimo, como pasar una jeringa a través de estos barrotes. Y así, los adictos obtienen lo que necesitan. Así funciona la civilización.

-La civilización... -repetí. 
Sentí admiración, incluso orgullo por aquel joven. Sentí su gentileza por querer ayudarme. Pero me angustié enseguida cuando tuve que explicarle que, en realidad, se trataba de un mero rumor. Escuchó mi descargo y su rostro se llenó de desilusión. Hice lo que pude para que no se sintiera mal.

-No se preocupe... Me alegra verlo bien de salud y a punto de salir del hospital —dijo con un tono aún más amable que el anterior-. Usted llegó a este estado porque pensaba y se esforzaba demasiado, sensei, pero pronto va a retomar su compostura. Cuando le den el alta, por favor venga a visitarme. -Escribió su dirección en un papel, también dibujó un plano-: Es un salón de go en un barrio bastante concurrido; no es mi casa, pero estoy ahí siempre durante el día -terminó de decir esto, saludó y se marchó.

A los pocos días me dieron el alta. Esa misma noche terminé en un barrio al que nunca había ido, solo y con pocas ganas de volver a uno conocido donde tomar algo. Sin embargo, di vueltas y vueltas sin encontrar un bar "decente". Entonces recordé que cerca de allí estaba el salón de go que me había indicado Kimigorō. Pensé que sería una buena oportunidad para devolverle su gentileza y se me ocurrió invitarlo a tomar unos tragos. De inmediato di con el lugar.

- ¿Estará Kimigorō Ōjî̀ - pregunté en la entrada.

$\mathrm{Al}$ escuchar esto, dos chicas que se pasaban dinero entre ellas empezaron a cuchichear.

- ¡Ah, está hablando de Kimi! -gritó una de ellas.

- ¿Qué? ¿Kimi?

Ambas se rieron.

-Kimi no está. Fue a tomar una ducha al baño público y ya no va a volver hoy.

${ }_{-}$Y hay algún lugar donde pueda encontrarlo?

-En su local.

$-¿$ ¿Su local?

- ¿No lo conoce? Se llama café La Góndola. Está a la mitad de aquel callejón. Kimi debe de estar por salir del baño público, así que va a llegar allí en cualquier momento. 
Le agradecí y avancé por una callecita donde había una serie de bares alineados uno tras otro. En cada puerta había chicas que invitaban a los hombres a entrar, a veces tirando de sus manos.

Encontré el café La Góndola y entré sin prestar demasiada atención. Supuse que Kimigorō era uno de los barman. Pero no. Miré alrededor y no había un solo cliente. Ni siquiera hombres; sólo las chicas que trabajaban allí.

-Disculpe, me dijeron que encontraría a Kimigorō Ōji aquí. ¿Por casualidad tienen un cliente regular con ese nombre? la chica.

-¿Kimi... Kimi-chan? Por supuesto, está aquí-respondió

Me quedé pensando en por qué usaban con tanta ligereza ese sufijo, chan, aunque, bueno, había leído que también así llamaron a una elefantita en el zoológico. Mientras, otra chica gritó hacia el fondo del bar:

-Kimi-chaaan, jun cliente!

Lo que sucedió después dudo que lo imaginen siquiera las personas adictas a esos programas de premios en la radio, Veinte preguntas o Adivine la palabra. Tic-tac, tic-tac, responda dentro de los próximos treinta segundos para probar su inteligencia...

El joven Kimigorō Ōji se acercó. Pero no era "el” joven Kimigorō, sino Kimi-chan, una mujer. O más bien, uno y otra. Al parecer, este tipo de cosas es común en el barrio de Ueno. Para mí, sin embargo, que sólo lo había conocido como un musculoso obrero, sin rastros de feminidad, descubrir ese rasgo de su persona me dejó boquiabierto. Tendrán que disculparme por pensar así. Supongo que sería peor algo del estilo del Dr. Jekyll y el Sr. Hyde.

Kimigorō llevaba ropa de mujer, sí. Pero más allá de eso, no había nada femenino en él... ella. Un joven que busca hombres para venderse suele hablar como mujer. No así Kimi. Y tampoco es que estuviera conteniéndose por mí; era evidente que actuaba con absoluta naturalidad. Lo comprobé luego, al ver cómo se dirigía a los otros hombres que empezaron a llegar al lugar. 
-Muchas gracias por venir - dijo con algo de timidez, pero sin rastros de vergüenza-. Ésta es la forma en que me gusta moverme por el mundo, sensei. No significa que me prostituya. No soy ese tipo de persona imprudente. Sólo me gusta vestirme de mujer porque así entretengo a todos y me veo mucho mejor. Al principio fue sólo un juego, como en una fiesta de disfraces. Me intrigaba saber cómo lo tomarían los demás. Ya sabe que no soy una persona muy popular que digamos. Para ser alguien tendría que haberme unido a una organización criminal... ¿Era ésa la vida que yo quería? Ahora, sin embargo, como mujer, nadie se pelea conmigo y me evito la violencia propia del mundo de la mafia. Claro que, viéndome así, algunos clientes creen que pueden ser más tacaños en los negocios. Pero personalmente me da más seguridad. Además, es la coartada perfecta para mi yo traficante. En fin... - hizo una pausa-. Quisiera aprovechar y pedirle disculpas por haberle llevado la droga el otro día. No sé por qué lo hice si yo tampoco la consumo. Es más, soy una persona obsesionada con la salud, que se preocupa por cuidar a su esposa y a sus hijos... Aunque ella no sabe que me travisto, como se imaginará, je, je.

$\mathrm{Su}$ esposa era una preciosura. Engreída y fría, pero una preciosura. Cuando lo conocí durante la guerra, Kimigorō llevaba una vida que era la envidia de todos, justamente porque la familia de su esposa era dueña de campos. Sin embargo, debido a eso, él nunca podía negarse a lo que ella propusiera. Se volvió impaciente, quiso ganar una fortuna de un día para otro y fue así como un chico tan bueno, tímido y modesto, terminó involucrándose con salones de apuestas. Cuando una mujer inculta toma el control de las finanzas domésticas se convierte en una déspota sin control. Ver el modo en que manejaba a su esposo me resultaba intolerable. De no haber sido por esa tirana, él habría seguido siendo un obrero honesto sin la necesidad de enredarse en el juego y menos aún de travestirse para esconder su yo traficante. En los bares, Kimigorō se emborrachaba con sólo tomar dos vasitos; siempre terminaba regalándole sus tragos a los demás. Hasta en eso podía verse su sometimiento. 
-Quiero llevarlo a un lugar especial esta noche -me dijo cuando regresó de ponerse ropas de hombre-. Un lugar de... $\mathrm{mmm}$, dudosa reputación. Pero mientras esté conmigo, nadie le va a hacer nada. Acompáñeme, sensei, así le muestro otro de los submundos de nuestra sociedad.

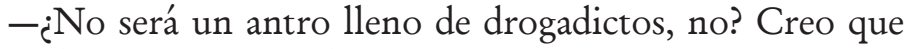
me haría mal ver algo así.

-Parece como si ahora le tuviera fobia a las drogas, sensei, je, je... Pero quédese tranquilo. Es un lugar al margen de la ley por otras razones.

Hizo un gesto para que lo esperara y se fue a un rincón a hablar con una de las chicas. Al rato regresó y salimos. $\mathrm{Me}$ llevó por unos callejones que yo desconocía o que no reconocí debido a la borrachera que me habían dejado los fuertes tragos de su local. Llegamos a una casa recién construida y elegante. Pensé que era un machiai, esos lugares a donde uno va a buscar geishas. Pero no. Era un ryokan, un albergue tradicional japonés. No era ése el barrio en el que uno esperaría encontrar un ryokan (tampoco un machiai para el caso). Pero resultó que por dentro era un lugar acogedor y con un baño compartido impecable. Además, no había otros clientes.

- ¿Éste es otro de tus negocios? - pregunté.

- No. Aunque ahorrara cien años no podría tener un lugar así, sensei. Es... ¿cómo llamarlo? Ni siquiera los dueños saben. Querían reabrirlo como restaurante, pero vaya uno a saber. Por ahora funciona como un mero hotel, aunque no como uno de esos prostíbulos de los años de la guerra. Por eso no tiene clientes, y, más allá de las tres o cuatro personas que lo conocen, el lugar está siempre tranquilo.

Nos habíamos servido unos tragos cuando llegó la chica con la que Kimigorō había hablado en un rincón del café La Góndola. No era fea, pero tampoco era muy linda. Proporcionada de cuerpo, de estatura mediana. Daba la impresión de ser fría y silenciosa.

$-¿$ Tendría que haberle adelantado sobre este encuentro, sensei? Pero eso no tendría nada de divertido. 
Kimigorō, que casi nunca tomaba nada y se la pasaba llenando el vaso de los demás, tenía los ojos rojos. Le pasó un trago a la chica. Ésta lo agarró y lo bebió de golpe. Se llamaba Yoshiko. Yoshi-chan.

-Yoshi-chan nació en la misma provincia que yo. Su padre era el director de la primaria donde estudiábamos juntos, aunque cursó la secundaria en un colegio de chicas; después de eso estudió dibujo y por último se mudó a Tokio, donde terminó siendo vecina de un famoso tatuador. Eran los años de la guerra, tan distintos a los actuales, cuando un tatuador era algo extraño. Fascinada, Yoshi-chan empezó a sentir que era aburrido dibujar sobre papel y quiso hacerlo sobre su cuerpo: tatuarse, marcar su carne, experimentar la potencia del arte. Y aunque el tatuador rara vez recibía clientes, terminó aceptándola como su aprendiz. Así que Yoshi-chan se tatuó a sí misma, pero he aquí que no quedó conforme con el resultado. ¿No es común que al finalizar un trabajo para el que no estamos totalmente preparados sintamos que lo hemos hecho mal? ¿Qué hizo entonces? Se arrancó el pedazo de piel donde estaba el tatuaje. Sólo fue una parte pequeña del interior de su muslo, de modo que sufrió apenas un desmayo. Pero esto da cuenta de su personalidad: una artista hasta los huesos, alguien que se deja poseer por una obsesión endemoniada.

La chica no movió ni una ceja. La historia era bizarra e impensada, pero le faltaba algo que sustancialmente me convenciera de su contenido. Y eso se debía a la personalidad de la chica que tenía ahora enfrente. No percibí en ella a una artista obsesionada. Al contrario, al verla allí, en silencio, sin correr la mirada, haciendo ruido con la boca, sentí que su verdadera naturaleza no iba más allá de ese puñado de gestos frívolos y dispersos.

-Nuestra naturaleza es nuestra naturaleza y la de esta chica es sombría y obsesiva - continuó Kimigorō-. Hace lo que se le antoja. No busca clientes para trabajar como prostituta; no quiere ser una más en estos tiempos de chicas panpan. Pero justamente por eso se le hace difícil vivir el día a día, mucho más 
comprarse un kimono. El punto es, sensei, que es su seguidora desde hace un tiempo. Y como tiene la intención de dedicarse a la literatura, quiere pedirle a usted que sea su mentor. "Pero si se lo pido directamente voy a parecer una molestia", me dijo. Así que ya ve: arisca y silenciosa como es, me pidió que lo hiciera por ella.

El pedido me sonó sincero. Kimigorō no se hubiese tomado todas estas molestias por el mero hecho de presentarnos. Una idea relampagueó en mi cabeza: que había algo entre ellos. ¿Pero qué tipo de relación?

No podía dar una respuesta así nomás. Enseñar literatura es imposible si el discípulo no tiene un mínimo de talento. Claro que esta lógica nos lleva a preguntarnos si el talento es una causa o una consecuencia, si se nace con él o si se obtiene. Quizá no tenía que ver con eso y sólo me la estaba ofreciendo como amante. Y, para ser honesto, no era linda, pero tenía algo de encanto. Era silenciosa, amargada, sombría, sí, pero justamente eso me despertó las ganas de divertirme por lo menos una noche con ella. Por un instante, la lujuria del alcohol se adueñó de mí, pero en seguida recordé lo perturbador de su historia y me compuse.

-No importa cuánto uno se esfuerce. Si no se tiene talento nato, no se puede aprender nada. Así que no puedo aceptar su pedido sin verificar eso primero.

-Pero, sensei, ¿no es obvio que lo tiene? Por el momento, supongamos... No. Es más que una suposición. Se sabe que un genio y un loco se asemejan, porque ambos pueden ver cosas que los demás no. En ese caso, ¿`su locura no es también muestra de su incansable talento?

Era la primera vez que ese joven se comportaba de forma tan persistente sobre algún asunto. Contuve una risa sarcástica. Nadie sabía más que yo sobre ese tema.

-Tanto palabrerío sobre la genialidad de un loco, pero en el psiquiátrico tuve que ver con mis propios ojos cómo viven los locos. Los viste también. Son personas comunes y corrientes, con un gran sentido común. Te diría incluso que 
tienen más sentido común que la mayoría de la gente. Sí los caracteriza, sin embargo, el saber disimular esa naturaleza. Lo mismo que a los genios. Así, es imposible determinar si alguien es un loco o un genio a partir de un comportamiento excéntrico de su parte. Debemos agregar que el talento nato difiere según sea para la pintura, la literatura u otra cosa; una persona con talento para la pintura ve las cosas a través del color, mientras que una abocada a la literatura nació imposibilitada para ver más allá de las estructuras de las palabras. Sólo porque alguien actúe raro no significa que tenga talento para esto último.

-Ya lo va a entender, sensei. Va a entender que, más allá de las teorizaciones, los opuestos se parecen. Usted y Yoshichan, por ejemplo, son un sol-y-luna. El hombre es el sol y la mujer es la luna... y así los opuestos se conectan —concluyó Kimigorō bajando la cabeza.

Golpearon la puerta para avisar que mi baño estaba listo. Cuando terminé de bañarme, Kimigorō ya se había ido. Me llevaron a un cuarto con un futón tendido; me recosté y poco después se acercó Yoshi-chan, también bañada, y se acostó a mi lado. Me sentí incómodo, como si fuera a vigilarme incluso dormida.

— ¿Kimigorō siempre dice cosas tan raras? - pregunté.

La mujer soltó una risa como si se le hubiera soltado un tornillo. Como un reloj pequeño que empieza a retumbar de golpe y sin control.

- ¿Cómo va a tomarse en serio lo que dice ese hombre? ¿Usted es estúpido o no durmió bien? ¡Él es el loco! Vestirse de mujer... Podría entenderlo de un pervertido, ¿pero de él? Sea lo que sea, su cabeza funciona al revés que las del resto de las personas. ¿Cómo podría saber que yo tengo un tatuaje en mi muslo y que me lo arranqué? Es puro delirio suyo. Mire usted mismo. Mire si tengo un tatuaje o una cicatriz por habérmelo quitado.

La mujer me mostró su muslo. Efectivamente, no había nada allí. Su actitud volvió a darle un aire de prostituta común y corriente, lo cual me tranquilizó de inmediato. 
-Entonces todo eso de querer convertirte en artista...

-Bueno... pinté alguno que otro óleo, pero siempre por dinero. Eso no significa que sea artista. Hoy en día la gente es tan soberbia que se llama a sí misma como se le antoja -remató con un tono indiferente que disipó su melancolía de hacía un rato.

Yo, sin embargo, seguía confundido. Cuando Kimigorō había ido al psiquiátrico a darme la droga, no noté en él ningún indicio de locura. Pero, claro, así son los locos: nadie sabe de su condición hasta que tienen convulsiones o un brote psicótico. Fui testigo de esto muchísimas veces durante mi internación. Esto significa que, así como todos tenemos algo de criminal, también todos tenemos algo de loco. Que definir la locura es sólo una cuestión de límites arbitrarios.

No sé a qué hora nos dormimos. Acostumbrado a la rutina de insomnio que me acosaba en el psiquiátrico, donde me daban unos somníferos que hacían efecto apenas en la madrugada, me levanté temprano, desayuné algo y desperté a Yoshi-chan para indicarle que regresara a su casa. Entonces pude volver a dormir. Y lo hice profundamente, cansado de todo lo que había ocurrido. Cuando desperté otra vez, ya era pasado el mediodía y mi baño estaba listo. Terminé de bañarme y la dueña del ryokan apareció con una botella de sake. Ella y su marido vivían allí solos; no tenían hijos ni sirvientes.

-Kimigorō me dejó helado ayer -le dije mientras ella servía-. Me sorprendió verlo vestido de mujer, pero más aún la historia del tatuaje. Habló con tanta seriedad que en ningún momento creí que fuera una mentira. Pero no entiendo: si me acostaba con Yoshi-chan, la verdad saldría a la luz. Evidentemente era lo que quería... Ahora bien, ella dijo que él estaba loco, pero más allá de anoche, nunca me había dado esa impresión. Primero pensé que pasaba algo entre ellos, pero ahora me da la impresión de que es ella la que juega con él.

La dueña asintió en silencio. Así como nadie podía saber desde afuera qué sucedía en su casa, nada en ella revelaba su verdadera profesión. Pero definitivamente tenía algo de ma- 
dama. Una sonrisa siniestra apareció en su rostro, aunque de inmediato retomó la seriedad anterior.

-Kimi nos trae clientes todas las noches, pero es él quien se encarga de elegir para cada uno una mujer distinta. A veces lo hace pensando en cómo consentir los gustos de esos hombres; otras, en cómo hacer coincidir sus personalidades. Pero a veces lo hace también siguiendo su propio capricho, su propio deseo... Quizá le excita hacer esas conexiones. No es que esté loco, es sólo su forma de locura. -La mujer hizo una pausa que acompañó con un gesto de lástima-. A todos, sin embargo, les cuenta la misma historia: esa de la chica que se arrancó un tatuaje del muslo. ¿No le habló también del sol y la luna?

-Lo hizo... - respondí desconcertado-. Dijo que el hombre es el sol y la mujer es la luna. Que juntos son un soly-luna.

Otro largo silencio. Me sentí un estúpido por haber caído en ese jueguito morboso, por haber creído que la mujer de anoche era una artista genial y yo un literato genial y que juntos éramos como el sol y la luna. Le pedí a la dueña del ryokan que me explicara qué era exactamente eso de sol-y-luna. Ella respondió con una carcajada.

-Un Nichigetsu-sama, un Soliluna. Así lo llama él. Es algo en lo que cree con un fervor religioso, un ser divino que es el resultado de la unión entre un hombre y una mujer. Aunque también cree que él puede convertirse en eso por su cuenta con sólo travestirse. - Hizo una pausa en que mantuvo una cara-de-nada ante mi sorpresa-. Pobre, es un buen chico, pero le falla la cabeza. Algunas personas dicen que en realidad fue él quien se arrancó un tatuaje del muslo. Es sólo un rumor, pero escuché que tenía una amante que lo volvía tan loco que, cuando ella le pidió unir plenamente sus cuerpos, él se cortó el muslo para dárselo de comer.

No dije nada más. Dejé que terminara de esa forma mi primera jornada fuera del psiquiátrico. $\mathrm{Ni}$ siquiera me dieron ganas de confirmar el rumor; me conformé con creer que todo había 
sido una pesadilla. Me dije que hay cosas incomprensibles. Me convencí de que lo mejor es no intentar darles sentido. Volví a casa. Unos días después, más tranquilo, leí en el periódico que habían capturado al traficante de drogas Kimigorō Ōji. Ese día empezó este indetenible fluir de voces en mi cabeza. 
